\title{
Analytical Skills for Policy Practice: A Social Policy Framework to Address Corruption as a Social Problem for Development in Nigeria
}

\author{
Muhammad Bello Muhammad \\ Department of Sociology, Usmanu Danfodiyo University, Sokoto, Nigeria \\ ibnmuhd80@yahoo.com \\ Muddassir Ahmad Gado \\ Department of Sociology, Usmanu Danfodiyo University, Sokoto, Nigeria \\ muddassirag@gmail.com
}

Doi:10.5901/mjss.2015.v6n3s1p637

\section{Abstract}

Corruption is a dishonest exploitation or use of power for personal gain. It is the extreme act of immorality and depravity, the state of being corrupt and rotten. Corruption destroys the entire societal fabric as it undermines the effectiveness of government's social policies aimed at providing social or welfare services to citizenry; and even those policies aimed at fighting its continue existence. This paper examines critically the various ways through which corruption had became institutionalized in Nigeria and its subsequent impact on political culture and behaviour on the one hand and its implications for development on the other hand. The paper hypothesized that the institutionalization of corruption leads to an overall change in the value-system and norms of behavior in a society. This was eventually related exclusively to politics and the manifestations of corruption in the political arena were discussed.

Keywords: Corruption, Development, Skills, Social policy, Social problems.

\section{Introduction}

The Concept of Social Policy is relative and therefore has various definitions, as an academic field of study, it is one of those curious items, rather like an elephant, which we recognise when we see it but which is notoriously difficult to describe. It is at one and the same time, the theoretical pursuit of norms about how we think Society 'ought' to behave, but also the practical application and implementation of those policies that we consider to be 'social'.

Policy according to the Oxford Dictionary of Sociology- is a set of clearly articulated ideas about what should be done in a particular sphere, which is often set down in writing, and formally adopted by the relevant decision making body.

Social Policy can be defined as a deliberately taken decision or package of decisions by the State or Goverment,which is concerned with the provision of range of services, facilities, infrastructures, e.t.c.

Further more, Rittel and Weber (1973) argued that social policy primarily refers to guideline and intervention for changing, maintenance or creation of living conditions that are conducive to human welfare. Social policy is part of the public policy that has to do with social issues.

Thus, social policy deals with the distribution of resources, oppurtunities and life chances between different groups and categories of people. This means that every policy and programme of government may have social aspects. For example, Health and Education Services are primarily designed to raise general standards of health and learning (Donnison 1975:26).

Social Policy include policies concerning Social Security, Health, Housing, Education, Employment and some times even Law and Order. This constitutes the most widely accepted interpretation of social policy i.e provision of goods, services and the institutionalization of social justice. This view directs its attention to policies generated specifically within the usual list of social welfare fields, it ignores the key areas usually assigned to economic policy, which however have profound impact on welfare, such policies includes: fiscal policy, and policies targeted toward inflation and economic growth, while these are seen as economic policies, they are also social policies, in the sense that they have a major implication for welfare which cannot be divorced from the field of social policy (Aliyu et al 2009). 
The main objectives of the paper is to examines critically the various ways through which corruption had became institutionalized in Nigeria and its subsequent impact on political culture and behaviour on the one hand and its implications for development on the other hand by using secondary sources.

The paper poked at the whole scenario from the sociological perspective and the Durkheimian postulation that all behaviour is socially generated. And as such corruption should be seen largely as a social problem and not as emanating from individual dispositions. On the basis of the submission, some categorical imperatives were suggested in order to reduce the level of corruption.

The paper concluded by saying that any social problem deserves societal attention and collective solution. The government as such has the responsibility to educate, mobilize, socialize, enlighten and sensitise its citizens through regulatory authority towards a tradition of honesty, excellence, truth, diligence, integrity, honour, reputation, good name and other moral virtues that will lead to the establishment of a new social order.

\section{Importance of Social Policy}

The importance of Social Policy cannot be overemphasized because it helps us to meet human needs for education, health, housing and social security, e.t.c. Also, it allows us to use the analytical skills for policy practice as a social policy frame of reference to conceptualize, assess and address social problems. For example, Theodore Lowi provided us with a five fold Social Policy typology of action which entails- Regulatory Authority, Distributive mechanism, Redistributive channels, Capitalization, and Ethical consideration. It incorporates all the basic characteristics or elements of any policy action.

Therefore, social policy is a way of getting to know the material world and how people live in it. It also, helps to show the inequalities that exists between and among various classes of people in the society as well as exposing problems that may arise as a result of a wide gap in the quality of life among people, so that government can take steps to minimise and reduce the gap by providing policies that are aimed at wider distribution of resources among people (Aliyu et al 2009).

\section{Corruption as Social Problem}

According to Akindele (1995) corruption is undeniably a socio-political economic and moral malaise that usually holistically permeate all the nerves of any polity. It is contagious and malignant to the physiology of any political system. Once it sets into any part; it automatically contaminates all the strata of the system's socio-political structures in ways symmetrical to the spread of a bush fire.

The sociological approach tends to identify corruption as a social problem. A social problem connotes an act of a form of behaviour which constitutes concern to a significant proportion of the society to warrant a common solution by that society. The structural-functionalists regard social problems as serious behavioural deviations hindering the functioning of society; social problems are regarded as inhibiting the needs and goals of society.

It is hypothesized in this paper that when corruption becomes institutionalized in a society, it infiltrates into the value-system, it becomes a norm, part and parcel of culture and subsequently goes into the realm of behaviour. To this end, corruption becomes a social problem that must be critically and seriously addressed. Nigeria has long been treading the brink of this national catastrophe due to the almost uncontainable intensity of corruption of a viable, virile and stable polity. It also constitutes the greatest hindrance to the moral uprightness of the citizens. In this paper, the point of focus is on corrupt practices and the effects on the society vis-à-vis political culture and behaviour.

\section{Corruption and Its Impact On Political Culture and Behaviour in Nigeria}

Today, Nigeria has degenerated with basic cultural characteristics fast disappearing for the mundane. The most single canker worm that has eaten into the fabric of our society today is the problem of corruption. And this has so pervaded the nation that most Nigerians are corrupt in one way or the other. Nigeria is presently in a state of disequilibrium as activities in the various social institutions have become rather unethical and synonymous with decadence. Consequently, the Nigerian society is presently characterized by social malaise such as insecurity of life, poverty, armed robbery, all forms of corruption, moral degeneration, succession crisis, and a general lack of accountability by those entrusted with governance. This brings about the social policy maker's role in making the society a better place observing systematically changes in the society, evaluating them and making suggestions on the ways in which social problems can be tackled.

Typical of most social science concepts however, there are divergent opinions on what constitutes corruption. The 
concept according to Akindele (1995) has long been ideologically, morally, culturally, politically and intellectually elusive to the point of losing sight of its detrimental and parasitic influence on people and the society at large. Dwivendi (1967) argued that corruption includes nepotism, favouritism, bribery, graft and other unfair means adopted by government employees and the public alike to extract some socially and legally prohibited favours. Gibbons (1976) however defined corruption exclusively in terms of politics. According to him, political corruption is the use of a public office in a way that forsakes the public interest, measured in terms of mass opinion, elite opinion or both, in order that some form of personal advantage may be achieved at the expense of that public interest.

For the purpose of this paper, the definition of corruption given by Akindele (1995) is in place. Akindele defined corruption as any form of reciprocal behaviour or transaction where both the power/office holder can respectively initiate the inducement of each other by some rewards to grant (illegal) preferential treatment or favour against the principles and interest of specific organization (or public) within the society. Overall, corruption covers such acts as:

- $\quad$ use of one's office for pecuniary advantage,

- gratification,

- influence peddling,

- insincerity in advice with the aim of gaining advantage,

- less than a full day's work for a full day's pay,

- $\quad$ tardiness and slovenliness.

There is also the inevitable need to define the concept 'political culture'. Political culture simply refers to the values, beliefs, and attitudes that condition political behaviour. Political culture is made up of certain values, feelings, information, skills and political attitudes that are possessed by the members of the same polity. Thus, Corruption influences these values, beliefs and attitudes that makes up the political culture negatively.

\section{Manifestations of Corruption in Politics}

According to Akindele (1990) corruption in Nigeria include among others: Corruption ascendancy to political leadership through election rigging and genocidal political techniques; son of the soil philosophy; politics of expediency; doctrine of ten per centers, judicial fractionalization of human beings; political self-aggrandizement; political Hitlerism as a mechanism for retention of power; replacement of "we-feeling" by "me-feeling", contractor-controlled political machinery, uncurtailed lust for wealth, giving and receiving of kickbacks for government contracts, Police insistence on taking bribes as precondition for performing their duties, Bureaucrats indulgence in the act of falsifying accounts, false declaration of assets, violation of oaths of office, payment of money for government jobs not done or not well executed, pen-robbery and looting of the public treasury.

Babalola (1995) argued that corruption in politics occurs at two levels. The first level has to do with the various forms of corruption in politics at the law-making level while the second level is at the law-implementation level. At the first level, people try to influence law-making and policy decisions while at the second level, efforts are made by people to pervert the course of justice and influence judgements.

Summarily then, the perpetration of corruption in politics is done in the following ways:

(a) In voting there is outright buying of votes or even voters' cards during elections. The electorates are induced or 'settled' with some form of gratification usually money (Settlement syndrome - a new concept now used to describe all forms of corruption in Nigeria. It is otherwise known as "Egunje").

(b) Connivance with and the "settlement" of electoral officials in order to manipulate or falsify election figures. A glowing example was the 1983 elections in the second republic when the government in power manipulated election results with the connivance of electoral officials of the Federal Electoral Commission (FEDECO).

(c) Outright rigging of elections through other means such as thievery, threats to life, all forms of intimidation and the likes.

(d) Use of the power of incumbency and the state machinery. There is the 'Iron Law of African politics' which states that no government in power ever loses election. Office holders therefore makes use of all the available weapons at their disposal to suppress opposition and win elections at all cost.

(e) Use of money. Money is now a crucial and the most potent factor in Nigerian politics. The system does not make political aspiration available to everybody; it is available only to the rich and powerful. This is so, with the councillorship or the presidency of country, it is the same. You must be rich, powerful and well connected. No matter how popular you are, how credible or patriotic you are, your honour, reputation, integrity, records and desire to render selfless services, if you do not have money, you are a joker. Elective posts usually go to the highest bidder. 


\section{Impact on Political Culture and Behaviour}

The institutionalization of corruption in Nigeria is not without its telling effects on the emerging political culture and behaviour. Corruption has been on for so long in Nigeria as Akindele $(1990,1995)$ has aptly demonstrated through a retrospective analysis of politics from independence to date. He stated that no regime can be exonerated from corruption. It has now reached unprecedented levels most especially during the Babangida regime which saw the institutionalization of the 'statement' syndrome.

Corruption now appears to have become a permanent feature of the Nigerian polity. It had become completely institutionalized, entered into the realm of culture and the value-system; it is now a norm and no longer an aberration. The young ones are born into it, grew up in it, lived with it, and possibly die in it. The aged are not left out as they are resocialised and begins to conform to it.

Succeeding generations now see it as part and parcel of the social order and the normative system. Cultural transmission takes place and as such behavioural traits which confirms with corruption begins to emerge.

At the first stage, corruption and the value-system run on parallel lines. This leads to the emergence of a counterculture which runs counter to the existing norms in the society. At the third stage, corruption begins to enter into the realm of the normative system, a stage of partial institutionalization. At the fourth and the fifth stages, corruption becomes completely institutionalized, it becomes a norm, part and parcel of the culture while at the sixth stage socialization and resocialization for the aged begins and people now accept corruption as a way of life. At the final stage, new forms of behaviour merges which runs counter to the old social order but conforms with the new value-system in which corruption has been completely institutionalized and entrenched. The new social order becomes the yardstick for measuring behaviour. Corruption now governs the society.

\section{Impact of Corruption on Development}

From the previous arguments in this paper, it is clear that corruption is a cankerworm that has eaten into the fabric of our society. It has caused decay and dereliction within the infrastructure of government and the society in physical, social and human terms.

Corruption has been responsible for the instability of successive government since the First Republic. Corruption has contributed immensely to unbridle the FG and looting most especially in public offices. Again this had virtually turned Nigeria into the land of starvation and debtor nation in spite of the nation's enormous resources.

With the institutionalization of corruption, there can be no sustainable development, nor political stability. By breeding and feeding on inefficiency, corruption invariably strangles the system of social organization. In fact, corruption is literally the anti-thesis of development and progress.

\section{The Way Forward}

The sociological perspective does not regard a particular form of behaviour as the problem of the individual, but regards the individual behaviour as emanating from the social order in which the individual lives. This agrees with the Durkheimian postulation that all behaviour is socially generated. This perspective thus regards corruption as a social problem which assumes that society has contributed significantly to the manifestation of a form of behaviour and therefore the solution can best be found by focusing on the society rather than the individual who exhibits the behaviour.

The sociological perspective will therefore regard the institutionalization of corruption in Nigeria as a normal fall-out from the increase in moral decadence in the society as can be seen in all the various social institutions that makes up the society. The widespread corruption is a reflection of the profound changes in the value-system. The value-system unlike in the past when it was founded on honesty, hard work, trust, good name, selfless service, and integrity is now titled towards dishonesty, distrust, huge profit for little work and the acquisition of wealth all at the expense of good name, honour, reputation and integrity. In such a social order, it is unrealistic to have individuals who are 'saints' or 'angels' and who will remain uncorrupted! Within the context of such a decadent society. Within this context it is normal or rational for individuals to seek the same means (even illegal ones) which others are adopting or embracing in order to achieve certain goals and aspirations. The philosophy is if you can not beat them, then join them.

This situation can be better understood if one notes that the breakdown of the normative system and the subsequent institutionalization of corruption were systematically achieved by the executive arm of government through the deliberate corruption of the various institutions in the polity. The institutionalization of corruption during the Babangida regime and its perpetration in the on-going transition all attests to this fact. 
Having accepted that corruption is now part and parcel of the value-system, the logical question then is: what is the way out? When you cut a tree at the top, the tree grows up again, but when you uproot the tree, it dies completely. From this background, it is better to take care of the roots of corruption rather than the symptoms. What then are the roots of corruption in politics in Nigeria? There are two main factors responsible for these and they are discussed below.

First is the problem of 'Poverty' while the second factor has to do with bad governance and leadership. Poverty remains the main root and the anchor of corruption in Nigerian politics. Poverty has increased over the past few years in line with the deterioration in the economic and social conditions in the country. According to the Human Development Report (HDR) in 1996, most Nigerians live below poverty line. The gap between the rich and the poor is so wide that the rich ones can afford to buy even the conscience of the poor ones. There is lack of social security while unemployment has reached alarming levels. Unemployment and poverty go hand-in-hand. And poverty is the bane of an unjust and inequitable society. It is aggravated by failure to assure equality of opportunity for all the citizens. The people now become extremely vulnerable to all kinds of social vices which include corruption. They are hurt, damaged and discounted by the very society that should protect them, promote their interest and welfare. Their past is blighted, their present compromised and their future endangered, mortgaged and at risk.

Ake (1991) asserted that man cannot live without bread and this natural need for bread influences man's behaviour in virtually all spheres of his life. Severe material shortages in a polity prove much more authoritative and a determinant of man's behaviour in politics. If man's behaviour is to be controlled and become predictable - the socio-economic foundations of the polity must be one that ensures a fair standard of living. Corruption cannot be eradicated in polity where the material foundation for it does not exist. Poverty is a principal, perhaps the principal obstacle to the eradication of corruption.

All the above combined together makes people vulnerable and susceptible to corruption. Poverty makes people succumb quite easily to pressures and temptations. No wonder people can be easily 'settled'. As a result of the high level of unemployment, many people do not have any visible means of livelihood and as a last resort make politics a vocation and sources of livelihood. This category of people is ready to do anything whether legal or illegal to survive. In order to eradicate corruption in politics, the gap between the rich and the poor must be closed so that no man will be rich enough to buy his fellow men. There must be social security schemes that will enhance people's welfare while the level of unemployment must be drastically reduced. The argument is that people indulge in all forms of corrupt practices in politics because they are poor and left with no other rational options.

This is in line with Adebayo's opinion when he argued that corruption can only be eradicated in a just and egalitarian society, a land of bright and full opportunities for all its citizens. Not a country engulfed by poverty, deprivation and disparity; not a polity where to survive is becoming increasingly a miracle; not a political economy where life is short and brutish and there is a dangerous regression to parochialism.

The second factor has to do with bad governance and leadership. At all levels, Nigeria has leadership problems. From the first republic and up till now, the problem of leadership has been the bane of Nigerian politics. The leadership is corrupt while all sorts of patron-client relationships are established in order to remain in office. The struggle for power by those who lack it on the one hand, and the efforts of those who have it to consolidate their positions on the other hand is one of the roots of corruption in Nigeria. In Nigeria, the state is the primary source of private wealth accumulation and this in turn makes the struggle for control of power so intense. Added to this is the "winner takes all syndrome" which makes people to struggle to win electoral contests at all cost. In the attempt to maintain their hold on power, people explore every avenue whether legal or illegal to remain in office. If the leaders are corrupt, it is both logical and rational to expect the followers to be corrupt too. This is the reality of the Nigerian politics where it is even the leaders that corrupt the followers.

\section{Conclusion}

The central theme of this paper is that corruption has been completely institutionalized in contemporary Nigerian politics and this is now reflecting in the political culture and behaviour. This paper emphasized that corruption should be seen as a social problem which should be tackled through concerted societal efforts rather than focusing on the individual. Since a social problem connotes an act of a form of behaviour which constitutes concern to a significant proportion of the society to warrant a common solution by that society. The Structural-Functionalists theory was used as the most revelant to the study because it regards social problems as serious behavioural deviations hindering the functioning of society; social problems are regarded as inhibiting the needs and goals of society. The emphasis is on the reconstruction of the society via a vis - eradication of poverty, enthronement of good governance, national reorientation programmes and the likes as a way to ensuring a new social order in the polity. Any social problem deserves a societal focus, attention and efforts. 
Above all, the society has the responsibility to educate, mobilize, socialize, enlighten and sensitise its members towards a tradition of honesty, excellence, truth, diligence, integrity, honour, reputation, good name and other moral virtues that will make the society a better place for the people.

\section{Recommendations}

The following recommendations were made:

(a) Introducing or launching national reorientation programmes to educate people on the crucial need to eradicate corruption in politics. The previous efforts in programmes such as Mass Mobilization for Social and Economic Reconstruction (MAMSER), National Orientation Agency(NOA); An agency that replaced MAMSER, War Against Indiscipline (WAI); Introduced during Buhari/ldiagbon regime, War Against Indiscipline and Corruption introduced by the Abacha administration (WAIC), are steps in the right direction. Leadership must be by example and as such the doctrines of such programmes must be enforced right from the top to the bottom. Perhaps, it is time to consider the establishment of a "National Ethics Commission" for this purpose. It is in recognition of the appalling state of corruption, that the Nigerian Political Bureau in 1987 in its recommendations emphasized the indispensability of a new political culture.

(b) The society must be demphasizing the use of money or wealth for recognition and for political contests. The influence of money as a factor in politics must be curtailed and discouraged. People should be encouraged to vote for people's qualities rather than money.

(c) The government must introduce an equitable wages and incentive system and improve other conditions of work so that the level of poverty could be reduced and the quality of life improved. This will inevitably reduce people's vulnerability and susceptibility to corruption.

(d) Prosecution of erring individuals- People found to be involved in any corrupt practice should be prosecuted and if found guilty should be blacklisted from politics. This will serve as deterrence to others. Since corruption is a relationship of 'give and take' both the giver and the receiver must be prosecuted as well. Nobody will give bribes if no one will receive it. And no one will receive bribes if no one will give it. This is the simple logic.

(e) Societal efforts must be geared towards the abolition of the "winner-takes-all syndrome" as this is what makes political contests a matter of life and death.

(f) The people should be given the right sense of values which should be inculcated in the people so that they could respect others for their honesty and not just for their wealth.

\section{References}

Ake, C. (1991); Rethinking African Democracy. Journal of Democracy, Winter 1991. Cited, statements by Chester Crooker, the former USA assistant Secretary of State for African Affairs.

Akindele, S. T. (1990); Corruption and Economic Retardation: A Retrospective Analysis of Nigeria's Experience since Independence. In: Readings in the Political Economy of Nigeria Since Independence, Bamisaye, O. A. (ed.). Lagos Ventures Limited, Nigeria.

(1995); Corruption: An Analytical Focus on the problems of its Conceptualization. Ife Psychologia 3(1).

Aliyu and et al (2009); Class Presentation on Social Policy. BUK, Unpublished.

Babalola, A. (1995); Corruption and Political Crisis in Nigeria: A Sociological Viewpoint.

The Conference Proceedings of the Nigerian Anthropological and Sociological Association December 1995.

Bamisaye, O. A. (ed.) (1990); Readings in the Political Economy of Nigeria Since Independence. Lagos Ventures Limited, Nigeria.

Dennison, D. V. (1975); An Approach to Social Policy, Dublin. National Economic and Social Council, Republic of Ireland Stationary Office.

Dwivendi, O. P. (1967); Bureaucratic Corruption in Developing Countries. Asian Review, April 1967.

Gibbons, K. M. and Rowat, D. C. (eds.) (1976); Political Corruption in Canada. Toronto: McClelland and Steward.

HDR (Human Development Report) (1996); Human Development Report. The Guardian, Monday July 21st 1997, p. 40

Kurawa, S. S. (2010); Lecture Notes on Theory and Research in Social Policy. Unplished.

Marshall, G. (1998); Oxford Dictionary of Sociology. London. Oxford University Press. 
ISSN 2039-2117 (online) ISSN 2039-9340 (print)
Mediterranean Journal of Social Sciences MCSER Publishing, Rome-Italy
Vol 6 No 3 S1 May 2015 